\title{
Psycho Oncology
}

\section{Keshav Sharma*}

Department of Cancer Biology, Gurgaon, India

*Corresponding Author: Keshav Sharma, Department of Cancer Biology, Gurgaon, India.

\section{The beginning of psycho oncology}

Psycho oncology found footing in the mid 1970s, when it was realized that the stigma, "cancer means death" needed to be addressed.

Psycho oncology covers two major dimensions of cancer:

- $\quad$ Firstly, the psychological response of patients and their caregivers to the disease at all the stages.

- Secondly, psychological, behavioural, social, and ethical factors that may influence the disease process.

Over the period of time psycho oncology became a sub specialty of oncology. It provides the psycho social services to patients and families throughout all the phases of the cancer continuum including prevention, diagnosis through survivorship, terminal phase/ care, and bereavement.

Regardless of the prognosis, cancer causes some level of anxiety and depression. Psycho social services include individual, family, group counseling, education, advocacy, discharge planning, case management, and program development.

\section{Who is a psycho oncologist?}

Globally, a psycho oncologist is an interdisciplinary. A mental health professional who is psychiatrist, clinical or counseling psychologist, or a social worker holding a diploma/M.phil/P.hd in psycho oncology with mandatory practice under the supervision of a psycho oncologist in a cancer care setup is eligible to practice in this field.

\section{It's importance}

It is important to identify and address psychosocial issues through the course of and post the treatment of illness. Psychological morbidity among cancer patients tends to be high because of stigma attached to it. Emotional distress, depression and anxiety are problem in their own way and make it harder for the patients to cope with treatment. In certain types of cancer diagnosis llung cancer and head and neck cancer) guilt is associated due to tobacco and alcohol use which adds to the patients' distress.

Emotional and psychological support during the diagnosis and treatment may significantly improve the quality of life and the patient's ability to cope with the treatment. Psychological support during the course of illness helps reduce stress and anxiety, gives patients a greater sense of control and informs them of their probable experience during the course of illness and treatment.
Received: February 24, 2020

Published: April 17, 2020

(C) All rights are reserved by Keshav

Sharma.

\section{The role of a psycho oncologist}

Psycho oncology services provide support to the patients and their caregivers, helping them cope with the stress and the worries of the diagnosis. The physically demanding nature of their treatment process as well as the short term and long term side effects often result in emotional distress and psychological problems among the individuals affected by cancer, this eventually impacts their daily life.

Cancer has become the disease of the body and the mind, with questions of, "why me" depression, anxiety and adjustment issues, altered body image issues (hair loss, skin discoloration, mastectomy) during treatment and later interpersonal issues and those of sexuality too arise. The diagnosis of cancer affects not just one person but of all connected to the individual.

Hence, the Emotional support provided by the psycho oncologist aids throughout the treatment, survivorship or end of life care. Psycho educating about the treatment and its possible side effects helps patient as well as caregivers cope with the stressors of the treatment process, drastically reducing the rate of patients seizing to adhere to the treatment due to side effects.

Psychological counseling is imperative with cancer patients as they face the risk of substantial physical impairment, and the inability to perform routine activities and psychological and social levels resulting from the disease trajectory.

By providing required help to patients' and their caregivers coping is facilitated, restoring normalcy in their day to day life help them cope better emotionally and psychologically. Psycho oncology is a holistic end to end care program which begins at prevention level (primary prevention) where many individuals can be helped by spreading awareness regarding cancer prevention and lifestyle changes in today's time.

Every stage of cancer diagnosis comes up with psychological issues which vary in intensity and degree. In the initial stages the diagnosis is a shock, gradually when patients cope with this shock advancing to coping with the side effects of the treatment and the treatment itself. The consolidation of the treatment leaves behind issue of survivorship and constant fear of relapse, making the duty of a psycho oncologist even more crucial in assisting with greater quality of psychological wellbeing. 


\section{Assets from publication with us}

- Prompt Acknowledgement after receiving the article

- Thorough Double blinded peer review

- Rapid Publication

- Issue of Publication Certificate

- High visibility of your Published work

Website: https://www.actascientific.com/

Submit Article: https://www.actascientific.com/submission.php

Email us: editor@actascientific.com

Contact us: +919182824667 